\title{
LEACHING OF LEAD FROM CLINOPTILOLITE AT ACIDIC CONDITIONS
}

\author{
Y. PETRAKAKIS \\ E. MYLONA \\ D. GEORGANTAS \\ H. GRIGOROPOULOU*
}

Received: 22/01/07

Accepted: 02/04/07

\author{
Laboratory of Chemical Process Engineering \\ Section of Process Analysis and Plant Design \\ School of Chemical Engineering \\ National Technical University of Athens \\ Zografus Campus, GR-15780, Athens, Greece
}

\begin{abstract}
The leachability of $\mathrm{Pb}^{2+}$ from natural greek clinoptilolite was investigated according to the standard procedures TCLP/EPA/RCRA (1311), EPA Methods 1310, 1320 and DIN 38414-S4. Through SEM/EDAX analysis it was shown that lead was uniformly loaded onto the particles subjected to acid treatment. Sorption was fast during the first few hours and equilibrium was practically attained after $24 \mathrm{~h}$. $\mathrm{pH}$ was the dominant factor affecting leaching and for values 3 and higher less than $1 \%$ of the metal was leached out while at $\mathrm{pH}=1$ up to $20 \%$ of the lead initially present on the solid was leached out. At 1.5 and 2, lead was re-adsorbed after initial leaching. \% leaching after $24 \mathrm{~h}$ was found to increase with increasing initial load (17 to $44 \%$ for 15 to $\left.100 \mathrm{mgPb}{ }^{2+} / \mathrm{g}_{\text {clin }}\right)$. Agitation rate $(50-180 \mathrm{rpm})$ and particle size $(1.4-2 \mathrm{~mm}$ and 5-6 $\mathrm{mm})$ did not affect leaching. Higher temperature $\left(25-40{ }^{\circ} \mathrm{C}\right)$ resulted in increased leaching rates. Despite the limited number of data, leaching seems to follow third-order kinetics. Finally, exposure to acid conditions increased markedly the specific surface (from 35.1 to 79.4 $\mathrm{m}^{2} \mathrm{~g}^{-1}$ ) and lowered the average pore diameter (from 80.8 to $42.9 \AA$ ) of the clinoptilolite particles.
\end{abstract}

KEYWORDS: clinoptilolite, lead, leaching, acid treatment.

\section{INTRODUCTION}

Heavy metals are well-known and wide-spread pollutants of surface waters, due to their use in various industrial processes and ultimate discharge to the environmental systems of air, water and land. Their severe toxicity imposes treatment of wastewaters, before safe disposal. Heavy metal removal from wastewater is usually practiced through physicochemical processes. Ion exchange is actually one of the most widely used methods for low metal concentrations. Natural and synthetic materials are used in such processes, either in batch mode or in flow-through systems, depending on the specific case. Synthetic materials have many advantages, namely a pre-designable selectivity in cases of the simultaneous presence of many ions. They are however high-cost materials and therefore regeneration is usually applied. On the other hand, natural materials such as zeolites and clays are abundant, in exploitable deposits, and low-cost. They have however varying structures, and therefore their properties and metal removal effectiveness cannot be estimated without pilot tests. Zeolites are eventually being modified prior to application, in an attempt to produce a solid with more exchangeable sites. This pretreatment might be cost-effective since they can be used during several metal removal cycles, with intermediary regeneration.

Clinoptilolite is a natural zeolite widely used in environmental applications, namely for the removal of $\mathrm{NH}_{3}, \mathrm{~Pb}^{2+}, \mathrm{Hg}^{2+}, \mathrm{Cd}^{2+}, \mathrm{Zn}^{2+}$ etc from aqueous solutions (Tsitsishvili et al., 1992). The adsorption/ion exchange of these substances on clinoptilolite has been extensively studied, regarding kinetics, equilibrium and selectivity (Inglezakis et al., 2002). Selectivity order has been obtained in complex mixtures and in several operation schemes and the following orders are proposed for Na-clinoptilolite, which shows best ion exchange potential: 
$\mathrm{Pb}^{2+}>\mathrm{Ag}^{2+}>\mathrm{Cd}^{2+}>\mathrm{Zn}^{2+}>\mathrm{Cu}^{2+}>\mathrm{Na}^{+}, \mathrm{Pb}^{2+}>\mathrm{NH}_{4}^{+}>\mathrm{Ba}^{2+}>\mathrm{Cu}^{2+}>\mathrm{Zn}^{2+}>\mathrm{Cd}^{2+}>\mathrm{Co}^{2+}$ (Kesraoui et al. 1994; Blanchard et al., 1984).

On the other hand, used clinoptilolite, loaded with heavy metals, is usually being disposed, being a low-cost material for which regeneration is not cost-effective. Used clinoptilolite is eventually incorporated into cement together with nuclear wastes (Atkins et al., 1995), into sewage sludge compost (Zorpas et al., 2002) or land-deposited. The stability of such metalloaded zeolites is then of environmental importance, since eventual heavy metal leaching into surface or groundwater may constitute an environmental hazard.

Clinoptilolite is known to attract metals, which are not expected to leach out at neutral and alkaline conditions. The only possibility for leaching is during contact with acid solutions, as for example acid rain or acid leachates from industrial and municipal landfills. Acidity is known to influence heavy metal removal since $\mathrm{H}^{+}$can be considered as competitive cations in ion exchange processes (Inglezakis et al., 2003). Zeolites may also absorb $\mathrm{H}^{+}$in salt solutions of almost neutral acidity (Charistos et al., 1997). Standard procedures have been developed to evaluate potential metal leaching from solids. The most widely used is the Toxicity Characteristic Leaching Test (TCLP 1311) from EPA/RCRA. Other tests available are EPA Methods 1310, 1320 and DIN 38414-S4. The tests are based on the contact of the solid to be evaluated with acids (acetic, nitric/sulfuric) or with deionized water for 18-24 hours, eventually with repeated contact cycles, at $20-40^{\circ} \mathrm{C}$, at pH between 2,88 and 5 (U.S.E.P.A. 1986; 1992; 2004; DIN 3841-4, 1984).

In the present study the leachability of lead $\left(\mathrm{Pb}^{2+}\right)$ from natural clinoptilolite, batch-loaded with lead, was investigated according to the above stated standard procedures. In a next step, the influence of $\mathrm{pH}$, initial load of lead in clinoptilolite, agitation rate, temperature and particle size on kinetics of lead leaching was studied. In order to check uniformity of lead dispersion in the loaded particles, scanning electron microscopy with simultaneous chemical analysis (SEMEDAX) was used. Finally, the influence of acid treatment during the loading-leaching cycle on specific surface and average pore diameter of clinoptilolite was checked by nitrogen porosimetry (B.E.T).

\section{MATERIALS AND METHODS}

\subsection{Experimental procedure}

\subsubsection{Loading process}

Lead loading of clinoptilolite of various particle sizes was performed in a batch reactor. 10-50 $\mathrm{g}$ of solid were added to $5 \mathrm{~L}$ of lead solution at $500-5000 \mathrm{ppm} \mathrm{Pb}^{2+}$, stirred at $600 \mathrm{rpm}$ at ambient temperature for 3-7 hours. $\mathrm{pH}$ was adjusted to 4 in order to avoid $\mathrm{Pb}$ precipitation. Then the mixture was left to equilibrate for $24 \mathrm{~h}-8$ days. Clinoptilolite was separated by filtration and the remaining $\mathrm{Pb}^{2+}$ was measured in the supernatant.

\subsubsection{Leaching tests}

For the leaching tests, clinoptilolite samples loaded with lead as above were brought into contact with deionized water or acid solutions $\left(\mathrm{HNO}_{3}, \mathrm{HCl}, \mathrm{HNO}_{3} / \mathrm{H}_{2} \mathrm{SO}_{4}\right.$ and $\left.\mathrm{CH}_{3} \mathrm{COOH}\right)$ and kept at $30^{\circ} \mathrm{C}$ at a thermostated bath under agitation $(80 \mathrm{rpm})$. Ratio of solution to solid was 16 $\mathrm{ml} \mathrm{g}^{-1}$. If necessary, solution $\mathrm{pH}$ was monitored at the desired value. During the test, solution samples were taken and $\mathrm{Pb}^{2+}$ was measured in order to study kinetics. After $24 \mathrm{~h}$, clinoptilolite was separated by filtration and the remaining $\mathrm{Pb}^{2+}$ was measured to check equilibrium. For the EPA 1320 method, the solution/solid ratio was 20/1 and the whole procedure was repeated 5 times. In the second group of experiments, clinoptilolite samples, of various particle size, loaded with lead, were brought into contact with nitric acid at various $\mathrm{pH}$ values, and kept at $25-40^{\circ} \mathrm{C}$ under $140 \mathrm{rpm}$ (unless stated otherwise) for time intervals between 10 min and $24 \mathrm{~h}$ (unless stated otherwise). Clinoptilolite was separated from the supernatant by filtration and the $\mathrm{Pb}^{2+}$ present in solution was measured.

\subsubsection{Materials and analytical procedures}

The mineral used was collected from a deposit in the northern part of Greece (Skaloma, Thrace). It was ground and then sieved to different fractions of which 1.4-2 and 5-6 mm were used in the study. The samples were thoroughly washed with deionised water prior the ion 
exchange experiments in order to remove the surface dust. The chemical composition of the material was determined by SEM/EDS (scanning electron microscopy) measurements, using the model JSM-6100 of Jeol Scanning Microscope. Furthermore, X-ray diffraction measurements using XRD diffractometer (D500 of Siemens) and $\mathrm{N}_{2}$ porosimetry measurements (BET) using QUANTA CHROME NOVA 2000 series model were performed. Lead was measured in the supernatant with Atomic Absorption Spectrometry (Perkin Elmer model 350B spectrophotometer equipped with a Photron $\mathrm{Pb}$ Hollow Cathode lamp).

Lead nitrate of analytical grade (SERVA) and $\mathrm{HNO}_{3}, \mathrm{HCl}, \mathrm{H}_{2} \mathrm{SO}_{4}$ and $\mathrm{CH}_{3} \mathrm{COOH}$ (Merck) were used.

\section{RESULTS AND DISCUSSION}

\subsection{Clinoptilolite characteristics}

The chemical analysis of the completely dehydrated clinoptilolite samples is reported in Table 1 below (Elaiopoulos et al., 2005).

Table 1. Chemical composition of natural clinoptilolite

\begin{tabular}{c|c}
\hline Oxide & \% w/w \\
\hline $\mathrm{SiO}_{2}$ & 75,0 \\
$\mathrm{Al}_{2} \mathrm{O}_{3}$ & 12.6 \\
$\mathrm{~K}_{2} \mathrm{O}$ & 2.9 \\
$\mathrm{CaO}$ & 2.6 \\
$\mathrm{Fe}_{2} \mathrm{O}_{3}$ & 0.9 \\
$\mathrm{Na}_{2} \mathrm{O}$ & 0.7 \\
$\mathrm{MgO}$ & 0.6 \\
Other & 4.6 \\
\hline Si/Al ratio & 5.1 \\
\hline
\end{tabular}

In Figure 1 the XRD diagram of the sample is reported.

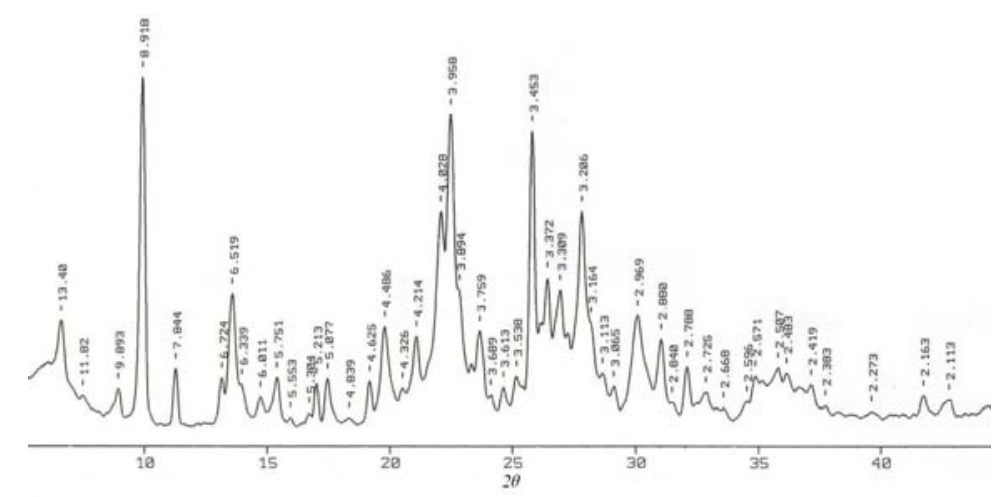

Figure 1. XRD diagram of natural clinoptilolite

It can be deduced that the main mineral component belongs to the clinoptilolite/heulandite group $(d=8.918 \AA, d=3.950 \AA)$ mixed with mordenite $(d=3.453 \AA, d=3,206 \AA)$. The presence of cristobalite $(d=4.028 \AA)$, moskovite $(d=9.893 \AA)$, smectite and feldspar was also assessed.

\subsection{Lead sorption on clinoptilolite}

The critical parameter for metal loading was proved to be the ratio $\mathrm{mgPb} / \mathrm{g}_{\text {clinoptillite }}$ in the contact solution. Sorption was fast during the first few hours and equilibrium was practically attained after $24 \mathrm{~h}$. The loaded samples had $12-103 \mathrm{mgPb}^{2+} / \mathrm{g}_{\text {clinoptilolite. }}$ SEM/EDAX analysis was used on a particle cross-section and representative images are given below in Figures 2a and $b$. 
It can be clearly seen that metal loading on the surface of the solid follows the progressiveconversion model (Levenspiel, 1998) and the samples used further for leaching experiments can be considered as uniformly loaded.

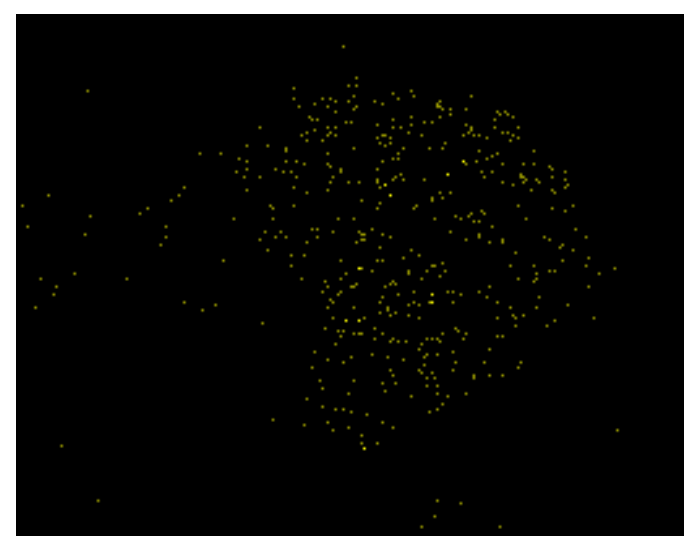

Figure 2a. Lead "spots" after $4 \mathrm{~h}$ impregnation time

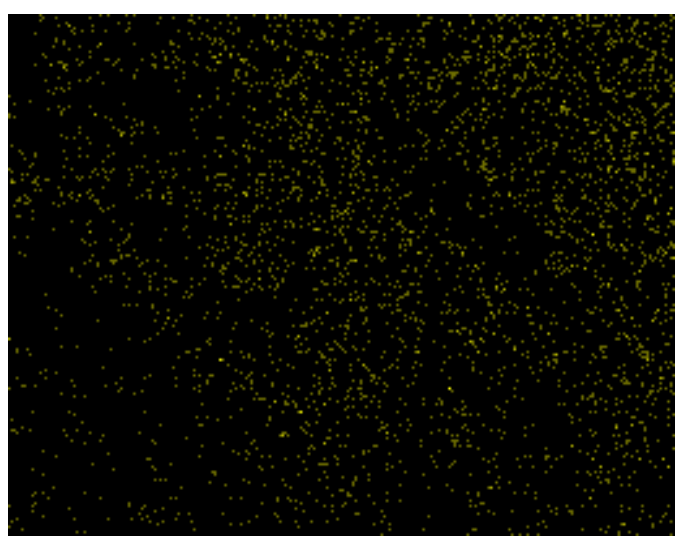

Figure 2b. Lead "spots" after 4 days impregnation time

\subsection{Standard leachability tests.}

The samples used contained typically $30 \mathrm{mgPb}^{2+} / \mathrm{g}_{\text {clinoptilolite. }}$ In Table 2 the test conditions are reported together with the experimental results, while in Figure 2 typical leaching evolution vs. time is presented.

$\%$ leaching was calculated according the equation

$$
\% \text { leaching }=\frac{\mathrm{mgPb}^{2+} \text { lost by clinoptilolite }}{\mathrm{mgPb}^{2+} \text { initially loaded on clinoptilolite }}
$$

Table 2. Experimental conditions and results for the standard leachability tests.

\begin{tabular}{cccc}
\hline pH & acid & test & \% leaching \\
\hline 1.0 & $\mathrm{HNO}_{3}$ & & 22.6 \\
1.5 & $\mathrm{HNO}_{3}$ & & 5.1 \\
2.0 & $\mathrm{HNO}_{3}$ & & 3.5 \\
3.0 & $\mathrm{HNO}_{3}$ & & 0.84 \\
4.0 & $\mathrm{HNO}_{3}$ & & 0.045 \\
1.0 & $\mathrm{HCl}$ & & 18.7 \\
3.0 & $\mathrm{HNO}_{3} / \mathrm{H}_{2} \mathrm{SO}_{4}$ & EPA 1320 & 1.07 \\
3.0 & $\mathrm{CH}_{3} \mathrm{COOH}$ & EPA 1311 & 1.65 \\
4.0 & $\mathrm{CH}_{3} \mathrm{COOH}$ & EPA 1311 & 0.424 \\
5.0 & $\mathrm{CH}_{3} \mathrm{COOH}$ & EPA 1310, 1311 & 0.053 \\
\hline
\end{tabular}

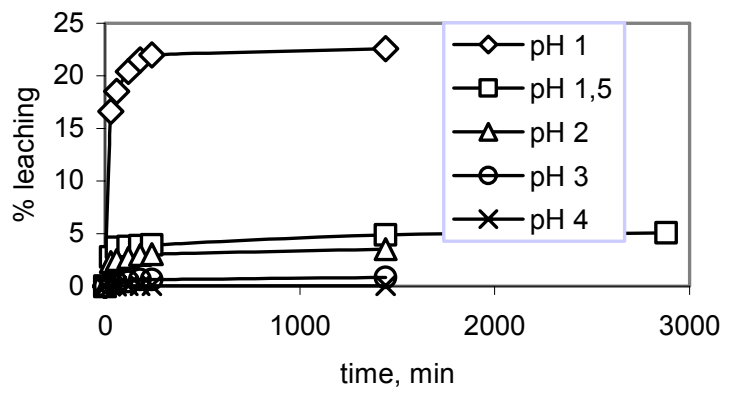

Figure 2. Time evolution for lead desorption from 1.4-2 mm particles

Lead solubilization experiments were also performed with water (tap or deionized) at $30^{\circ} \mathrm{C}$ for $24 \mathrm{~h}$ (DIN 38414-4), and in all cases less than $0.02 \%$ of the metal initially loaded was 
detected in the solution. According to the experimental data, it can be deduced that lead practically is not leached from clinoptilolite, except for strong acid solutions $(\mathrm{pH}=1)$.

\section{4. $\mathrm{pH}$ effect on leaching}

The influence of solution $\mathrm{pH}$ on lead leaching from clinoptilolite was further investigated at $40^{\circ} \mathrm{C}$ and the results are reported in Figure 3.

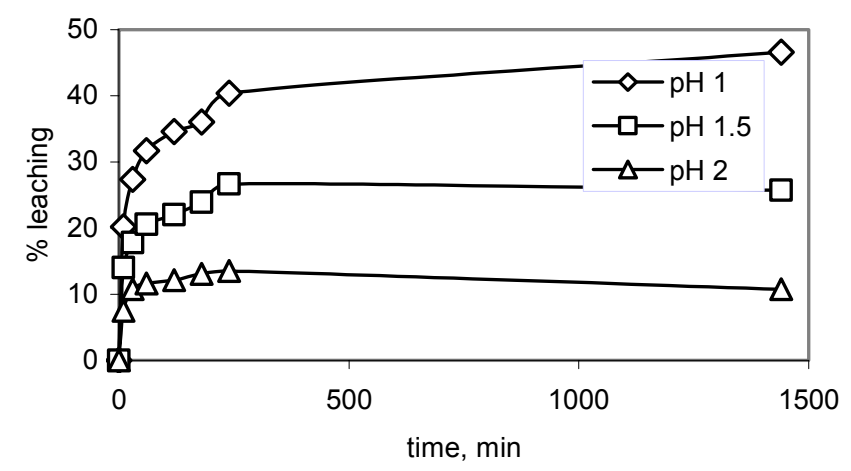

Figure 3. $\mathrm{pH}$ effect on desorption at $140 \mathrm{rpm}, 1.4-2 \mathrm{~mm}$ particles, $28 \mathrm{mg} \mathrm{Pb}{ }^{2+} / \mathrm{g}_{\mathrm{clin}}$

It can be seen that after a short-time-ion-exchange between $\mathrm{H}^{+}$and $\mathrm{Pb}^{2+}$ ions, equilibrium is shifted towards $\mathrm{Pb}^{2+}$ re-uptake and the effect is more pronounced for higher $\mathrm{pH}$ values. This could probably be due to the known strong preference of clinoptilolite for lead, but further investigation is needed.

\subsection{Initial metal load on leaching}

Higher initial lead loading results in lower \% leaching, of the same order of magnitude, as can be seen in Figure 4.

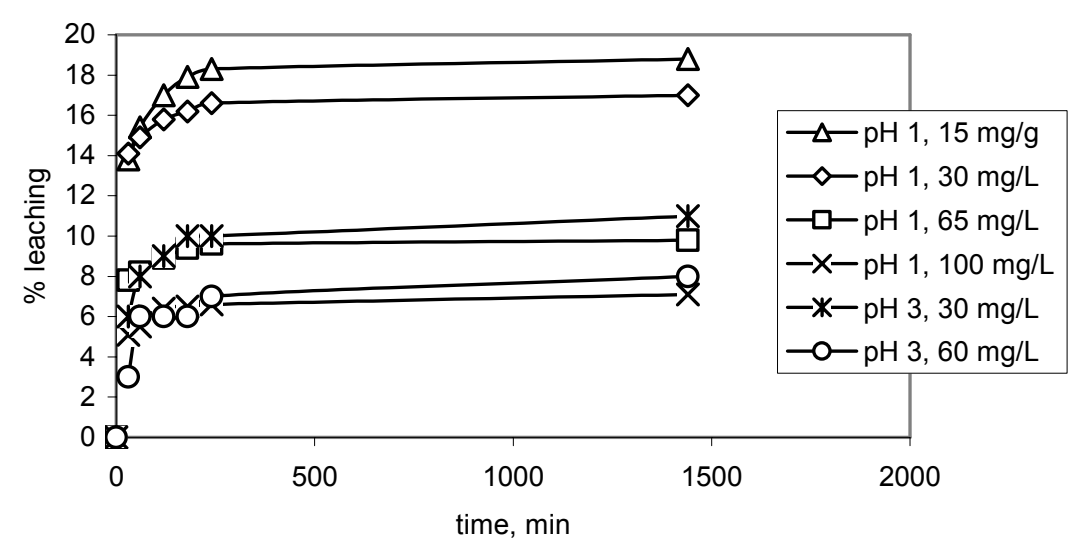

Figure 4. Initial load effect at $140 \mathrm{rpm}, 1.4-2 \mathrm{~mm}$ particles, $\mathrm{pH} \mathrm{1-3}$

\subsection{Temperature effect on leaching}

In Figure 5 experimental results are reported for different temperatures at various $\mathrm{pH}$ values. As it can be seen, temperature initially increases the rate of lead leaching, as theoretically expected. After some time however, as already stated, at "high" pH values lead is readsorbed, resulting in lower leaching values and this effect is more pronounced for increasing $\mathrm{pH}$ values. 


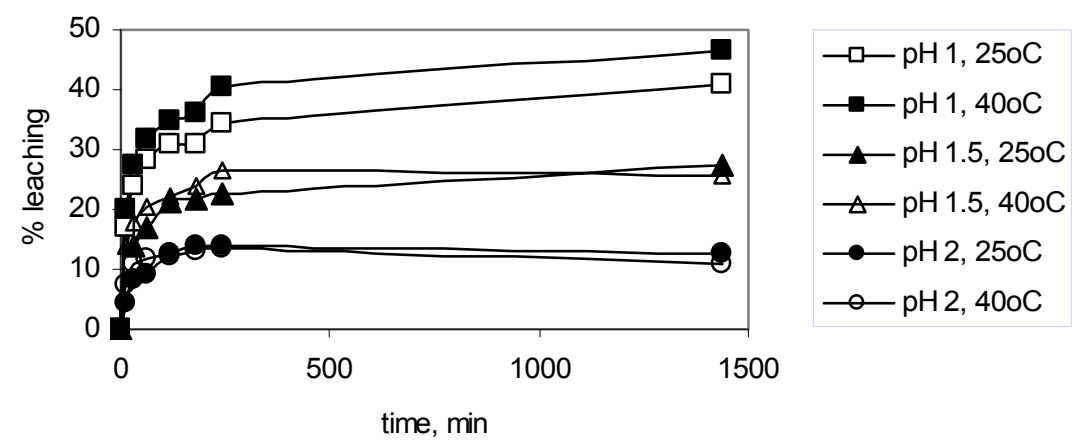

Figure 5. Temperature effect at $140 \mathrm{rpm}, 1.4-2 \mathrm{~mm}$ particles

\subsection{Particle size and agitation rate effect on leaching}

After sieving, clinoptilolite fractions of 1.4-2 $\mathrm{mm}$ and $5-6 \mathrm{~mm}$, loaded with the same amount of lead were compared for leaching and the results are presented in Figure 6. it can be seen that, within experimental error, no effect can be depicted on both kinetics and equilibrium.

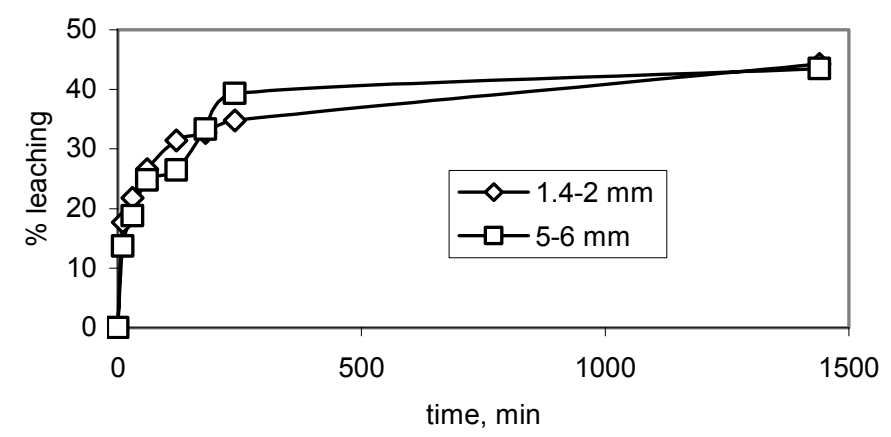

Figure 6. Particle size effect at $140 \mathrm{rpm}, 30 \mathrm{mg} \mathrm{Pb}{ }^{2+} / \mathrm{g}_{\mathrm{clin}}$

Agitation rate was varied from 50 to $180 \mathrm{rpm}$ and, within experimental error, no effect could be depicted.

\subsection{Kinetics of lead leaching}

Kinetics was investigated using the rate model $\mathrm{dq} / \mathrm{dt}=\mathrm{k} \cdot\left(\mathrm{q}-\mathrm{q}_{\infty}\right)^{\mathrm{n}}$, where $\mathrm{q}$ clinoptilolite load (meqPb ${ }^{2+} / \mathrm{g}_{\text {clin }}$ ), $\mathrm{q}_{\infty}$ load at infinite time (equilibrium), $\mathrm{k}$ rate constant and $\mathrm{n}$ reaction order. Few experimental data could be checked, because either equilibrium was not attained and in these cases reaction order was heavily dependent on the choice of $\mathrm{q}_{\infty}$, or re-sorption was evidenced and the model is clearly not applicable. There is limited evidence however that leaching follows third-order kinetics.

\subsection{Acid treatment effect on clinoptilolite characteristics}

The influence of acid treatment on the specific area and the average pore distribution of the solid particles were investigated and the results are reported in Table 3.

Table 3. Acid treatment effect on solid characteristics

\begin{tabular}{ccccc}
\hline $\begin{array}{c}\text { Treatment time, } \\
\mathrm{h}\end{array}$ & $\begin{array}{c}\text { Temperature, } \\
{ }^{\circ} \mathrm{C}\end{array}$ & $\mathrm{pH}$ & $\begin{array}{c}\text { Specific } \\
\text { surface, } \mathrm{m}^{2} \mathrm{~g}^{-1}\end{array}$ & $\begin{array}{c}\text { Average pore } \\
\text { diameter, } \AA\end{array}$ \\
\hline Raw material & & & 35.1 & 80.8 \\
1 & 40 & 1.5 & 71.1 & 48.4 \\
3 & 25 & 1 & 75.7 & 41.0 \\
24 & 25 & 1 & 79.4 & 42.9 \\
\hline
\end{tabular}


It can be noted that acid treatment affects markedly the solid structure, resulting in an increase of specific surface and a decrease of average pore diameter, creating thus additional micropores in the solid.

\section{CONCLUSIONS}

From the experimental findings the following conclusions can be drawn:

- $\mathrm{pH}$ is the dominant factor for lead leaching from clinoptilolite

- Lead may in certain circumstances be readsorbed on the solid particles

- Initial lead load increases \%leaching

- Higher temperature results to increased leaching rates

- Acid treatment increases specific surface and lowers average pore diameter.

\section{REFERENCES}

Atkins M., Glasser F.P., Jack J.J. (1995) Zeolite P in cements: Its potential for immobilizing toxic and radioactive waste species, Waste Management, 15(2), 127-135.

Blanchard G., Maunaye M., Martin G. (1984) Removal of heavy metals from waters by means of natural zeolites, Water Res., 18, 1501-1507.

Charistos D., Godelitsas A., Tsipis C., Sofoniou M., Dwyer J., Manos G., Filippidis A., Triantafyllidis C. (1997) Interaction of natrolite and thomsonite intergrowths with aqueous solutions of different initial $\mathrm{pH}$ values at $25^{\circ} \mathrm{C}$ in the preence of $\mathrm{KCl}$ : Reaction mechanisms, Appl. Geochem., 12, 693-703.

Deutsches Institut Fur Normung E.V. (1984) DIN 38414-4, German standard methods for the examination of water, waste water and sludge; sludge and sediments (group S); determination of leachability by water (S 4)

Elaiopoulos K., Grigoropoulou H., Perraki Th. (2005) Characterization of greek natural zeolite, dealumination and study of toluene adsorption, Proc. 5th Panhellenic Congress on Chemical Engineering, Thessaloniki, Greece, 377-380.

Inglezakis V.J., Loizidou M.D., Grigoropoulou H.P. (2002) Equilibrium and kinetic ion exchange studies of $\mathrm{Pb}^{2+}, \mathrm{Cr}^{3+}, \mathrm{Fe}^{3+}$ and $\mathrm{Cu}^{2+}$ on natural clinoptilolite, Water Res, 36, 2784-2792.

Inglezakis V.J., Loizidou M.D., Grigoropoulou H.P. (2003) Ion exchange of $\mathrm{Pb}^{2+}, \mathrm{Cu}^{2+}, \mathrm{Fe}^{3+}$, and $\mathrm{Cr}^{3+}$ on natural clinoptilolite: selectivity determination and influence of acidity on metal uptake, Journal of Colloid and Interface Science, 261, 49-54.

Kesraoui-Ouki S., Cheeseman C., Perry R. (1994) Natural zeolite utilization in pollution control: a review of applications to metal's effluents, J. Chem. Technol. Biotechnol., 59, 121-126.

Levenspiel O. (1998) Chemical Reaction Engineering, $3^{\text {rd }}$ Ed., Wiley.

Tsitsishvili G., Andronikashvili T., Kirov G., Filizova L. (1992) Natural Zeolites, Ellis Horwood.

U.S.E.P.A. (1986) Method 1320: Multiple extraction procedure http://www.epa.gov/epaoswer/hazwaste/test/pdfs/1320.pdf

U.S.E.P.A. (1992) Method 1311: Toxicity characteristic leaching procedure (http:// www.epa.gov/epaoswer/hazwaste/test/pdfs/1311.pdf)

U.S.E.P.A. (2004) Method 1310B: Extraction procedure (EP) toxicity test method and structural integrity test, Rev. 2. (http://www.epa.gov/SW-846/pdfs/1310b.pdf

Zorpas A., Inglezakis V., Loizidou M., Grigoropoulou H. (2002) Particle size effects on uptake of heavy metals from sewage sludge compost using natural zeolite clinoptilolite, Journal of Colloid and Interface Science, 250(1), 1-4. 